\title{
Pengaruh Teknik Bernyanyi dan Permainan Kartu Bergambar terhadap Sikap dan Perilaku Gizi pada Anak Taman Kanak-Kanak
}

\section{The Effect Technique of Singing and Games of the Picture Card on the Attitude and Nutrition Behavior in the Children of Kindergarten}

\author{
Eri Virmando ${ }^{*}$, Sapja Anantanyu ${ }^{2}$, Kusnandar $^{3}$ \\ ${ }^{1}$ Program Magister Ilmu Gizi, Universitas Sebelas Maret, Surakarta \\ ${ }^{2}$ Penyuluhan dan Komunikasi Pertanian, Universitas Sebelas Maret, Surakarta \\ ${ }^{3}$ Agribisnis, Universitas Sebelas Maret, Surakarta \\ (*virmandoeri26@gmail.com)
}

\begin{abstract}
ABSTRAK
Pendidikan gizi pada anak taman kanak-kanak merupakan upaya meningkatkan kesadaran berperilaku hidup sehat dalam konsumsi buah dan sayuran melalui Komunikasi, Informai dan Edukasi (KIE). Penelitian bertujuan menganalisis pengaruh pendidikan gizi melalui teknik bernyanyi dan permainan kartu bergambar terhadap sikap dan perilaku gizi anak taman kanak-kanak. Desain dalam penelitian ini adalah quasi eksperimental, dengan rancangan penelitian pre-post test with control group design. Subjek penelitian ini berjumlah 68 siswa dari 4 sekolah taman kanak-kanak yang ada di Kecamatan Tempilang, penelitian ini dilakukan pada bulan Januari- Maret 2018. Pendidikan gizi yang digunakan adalah teknik bernyanyi, permainan kartu dan intervensi gabungan. Hasil menunjukkan ada perbedaan sikap dan perilaku gizi pada pendidikan gizi. Intervensi gabungan mempunyai nilai tertinggi pada sikap dan perilaku gizi masing-masing sebesar $7.38 \pm 0.98$ dan 49.06 berbeda nyata dengan media intervensi lainnya. Terdapat perubahan sikap gizi baik yang meningkat sesudah intervensi $(97,1 \%)$ dari sebelum intervensi $(95,6 \%)$ dan perubahan perilaku gizi baik yang meningkat sesudah intervensi $(45,6 \%)$ dari sebelum intervensi $(79,4 \%)$. Pendidikan gizi melalui intervensi gabungan memberikan perubahan peningkatan sikap dan perilaku gizi pada anak taman kanak-kanak.
\end{abstract}

Kata kunci : Teknik bernyanyi, permainan kartu, sikap, perilaku gizi

\section{ABSTRACT}

Nutrition education in kindergarten children is an effort to increase awareness of healthy living behavior in consumption of fruits and vegetables through Communication, Information, and Education (CIE). This study aims to analyze the effect of nutritional education through the technique of singing and picture card games to the attitudes and nutritional behavior of kindergarten children. The design in this study was quasi-experimental, with pre-post test design with control group design. The subjects of this study were 68 students from 4 kindergarten schools in Tempilang Subdistrict, this study was conducted in January-March 2018. Nutrition education used was a technique of singing, card game, and joint intervention. The results show that there are differences in nutritional attitudes and behaviors in nutritional education. The combined intervention has the highest score on the attitudes and nutritional behavior of $7.38 \pm 0.98$ and 49.06 is significantly different from other intervention media. There was a change of good nutrition that increased after intervention $(97,1 \%)$ from before intervention $(95,6 \%)$ and change of good nutrition behavior that increased after intervention $(45,6 \%)$ before intervention $(79,4 \%)$. Nutrition education through joint intervention provides a change in the improvement of nutritional attitudes and behaviors in child kindergartens.

Keywords : Technique of singing, card game, attitude, nutritional behavior 


\section{PENDAHULUAN}

Pemerintah telah mencanangkan Gerakan Masyarakat Hidup Sehat (GERMAS) secara nasional dimulai dengan berfokus pada tiga kegiatan, yaitu: 1) Melakukan aktivitas fisik 30 menit per hari, 2) Mengonsumsi buah dan sayur; dan 3) Memeriksakan kesehatan secara rutin minimal 6 bulan sekali sebagai upaya deteksi dini penyakit yang dapat dimulai dari diri sendiri dan keluarga. ${ }^{1}$ Persentase pengunjung Posbindu dan Puskesmas yang kurang konsumsi buah dan sayuran di Indonesia pada tahun 2016 menurut kelompok umur tertinggi pada usia $\geq 60$ tahun $28,9 \%$, diikuti $26,1 \%$ untuk usia 35-59 tahun, dan usia $<15$ tahun adalah $25,8 \%$. Menurut provinsi, persentase tertinggi di Provinsi Bali (62,8\%), Bangka Belitung $(62,7 \%)$ dan Kalimantan Selatan $(61,5 \%){ }^{2}$

Upaya kegiatan dalam meningkatkan kesadaran berperilaku hidup sehat dalam konsumsi buah dan sayuran dilakukan promosi gizi melalui Komunikasi, Informai dan Edukasi (KIE) bagi keluarga, dan anak-anak. ${ }^{1}$ Masa pra sekolah merupakan periode waktu yang penting dalam pembentukan perilaku hidup sehat dan tidak sehat. ${ }^{3}$ Dalam masa pra sekolah anak lebih cenderung untuk belajar sambil bermain yang menjadi hal utama dalam meningkatkan perkembangan kognitif anak, fisik, mental emosional dan perkembangan sosial anak. Perkembangan perilaku anak terhadap makanan mulai meningkat ketika ditambah dengan intervensi dalam keterlibatan belajar sambil bermain. ${ }^{4}$ Selanjutnya, upaya membantu peningkatan pengetahuan anak terkait pemahaman tentang gizi (konsumsi buah dan sayur) dilakukan dengan cara pendidikan gizi. Hal ini akan berhasil sesuai dengan harapan apabila didukung dengan alat peraga dan media yang tepat untuk memperjelas pesan dan meningkatkan efektivitas proses pendidikan gizi. ${ }^{5}$

Penelitian menggunakan media lagu anakanak dapat memengaruhi tingkat pengetahuan gizi dan mengubah kebiasaan makanan sumber serat. ${ }^{6}$ Melalui pendekatan musik memberikan banyak manfaat, seperti merangsang fikiran, memperbaiki konsentrasi dan daya ingat serta meningkatkan aspek kognitif dan emosional. ${ }^{7}$ Upaya mengubah perilaku dan pengetahuan pada anak-anak diberikan melalui pendidikan gizi yang dikaitkan dengan perubahan perilaku dan pengetahuan tentang diet, penelitian dalam permainan kartu bergambar pada anak-anak terdapat peningkatan pemahaman tentang buah dan sayuran penting karena banyak mengandung vitamin $\mathrm{A}$, vitamin $\mathrm{C}$, vitamin $\mathrm{E}$, serat, dan air. ${ }^{8}$ Penelitian permainan kartu bergambar pada anak sekolah dasar dapat meningkatkan skor pengetahuan dan sikap sarapan sehat dibandingkan dengan media power point, wayang dan drama 9

Berdasarkan penelitian yang telah ada sebagian besar pendidikan gizi yang diberikan fokus pada pengetahuan gizi secara umum, belum berfokus pada peningkatan dan perubahan perilaku untuk mengonsumsi buah dan sayuran. Pendidikan gizi melalui teknik bernyanyi dan permainan kartu bergambar diharapkan memberikan banyak manfaat kepada anak usia dini terkait perubahan sikap dan perilaku untuk gemar mengonsumsi buah dan sayuran. Tujuan dari penelitian ini adalah menganalisis pengaruh pendidikan gizi melalui teknik bernyanyi dan permainan kartu bergambar terhadap sikap dan perilaku gizi pada anak taman kanak-kanak.

\section{BAHAN DAN METODE}

Desain penelitian ini adalah menggunakan penelitian quasi eksperimental, dengan menggunakan rancangan penelitian pre-post test with control group design. ${ }^{10}$ Populasi dalam penelitian ini adalah seluruh anak taman kanak-kanak di Kecamatan Tempilang yang dilakukan di TK Budi Utomo, TK Darul Amien, TK Negeri Pembina, TK Nurul Huda. Penelitian ini dilakukan pada bulan Januari - Maret 2018. Subjek penelitian ini adalah siswa/siswi kelas B dari 4 sekolah taman kanakkanak. Penarikan subjek menggunakan purposive sampling, dengan total subjek penelitian berjumlah 68 subjek dan dilakukan acak untuk menentukan kelompok intervensi teknik bernyanyi (TK Nurul Huda), Permainan kartu (TK Darul Amien) Gabungan (TK Negeri Pembina) dan kelompok kontrol (TK Budi Utomo).

Data penelitian yang digunakan pada penelitian adalah data primer meliputi karakteristik anak, sikap dan perilaku gizi tentang buah dan sayuran. Data terdiri dari pre test (sebelum diberikan intervensi) dan post test (setelah intervensi). Data pre test dan post test sikap dan perilaku gizi dikumpulkan menggunakan kuesioner dengan skala Linkert. Data yang telah dikumpulkan di- 
olah menggunakan uji paired sample t test, one way Anova dan uji post hoc. Uji paired sample t test digunakan untuk menganalisis perbedaan rerata sikap dan perilaku gizi, serta asupan buah dan sayur- an sebelum dan sesudah perlakukan pada kelompok intervensi. One way Anova dan uji KruskalWallis untuk menganalisis perbedaan rerata sikap dan perilaku gizi pada masing-masing kelompok

Tabel 1. Karakteristik Responden

\begin{tabular}{|c|c|c|c|c|}
\hline \multirow[b]{2}{*}{ Karakteristik } & \multicolumn{4}{|c|}{ Kelompok Penelitian } \\
\hline & $\begin{array}{c}\text { Kontrol } \\
\mathrm{n}=17(\%)\end{array}$ & $\begin{array}{c}\text { Gabungan } \\
\mathrm{n}=17(\%)\end{array}$ & $\begin{array}{c}\text { Permainan Kartu } \\
n=17(\%)\end{array}$ & $\begin{array}{c}\text { Teknik Bernyanyi } \\
n=17(\%)\end{array}$ \\
\hline \multicolumn{5}{|l|}{ Jenis Kelamin } \\
\hline Laki-laki & $5(29,4)$ & $4(23,5)$ & $9(52,9)$ & $9(52,9)$ \\
\hline Perempuan & $12(70,6)$ & $13(76,5)$ & $8(47,1)$ & $8(47,1)$ \\
\hline \multicolumn{5}{|l|}{ Umur (tahun) } \\
\hline 5 tahun & $1(5,9)$ & $8(47,1)$ & $10(58,8)$ & $8(47,1)$ \\
\hline 6 tahun & $16(94,1)$ & $9(52,9)$ & $7(41,2)$ & $9(52,9)$ \\
\hline \multicolumn{5}{|l|}{ Pendidikan Ibu (orang tua) } \\
\hline Tidak Pernah Sekolah & - & - & $1(5,9)$ & - \\
\hline SD & $4(23,5)$ & $6(35,3)$ & $7(41,2)$ & $5(29,4)$ \\
\hline SMP & $7(41,2)$ & $4(23,5)$ & $2(11,8)$ & $4(23,5)$ \\
\hline SMA & $5(29,4)$ & $6(35,3)$ & $5(29,4)$ & $5(29,4)$ \\
\hline Perguruan Tinggi & $1(5,9)$ & $1(5,9)$ & $2(11,8)$ & $3(17,6)$ \\
\hline \multicolumn{5}{|l|}{ Pekerjaan Ibu (orang tua) } \\
\hline Buruh & $9(52,9)$ & $8(47,1)$ & $8(47,1)$ & $7(41,2)$ \\
\hline Pedagang/wiraswasta & $6(35,3)$ & $7(41,2)$ & $5(29,4)$ & $4(23,5)$ \\
\hline Petani & - & - & - & - \\
\hline Pegawai swasta & $2(11,8)$ & $2(11,8)$ & $4(23,2)$ & $6(35,3)$ \\
\hline \multicolumn{5}{|l|}{ Jumlah Anggota Keluarga } \\
\hline 3 orang & $10(58,8)$ & $8(47,1)$ & $8(47,1)$ & $5(29,4)$ \\
\hline 4 orang & $5(29,4)$ & $4(23,5)$ & $6(35,3)$ & $11(64,7)$ \\
\hline 5 orang & $1(5,9)$ & $4(23,5)$ & $2(11,8)$ & $1(5,9)$ \\
\hline 6 orang & $1(5,9)$ & $1(5,9)$ & $1(5,9)$ & - \\
\hline \multicolumn{5}{|l|}{ Cara Makan Buah } \\
\hline Langsung dimakan & $17(100)$ & $17(100)$ & $17(100)$ & $17(100)$ \\
\hline Dibuat jus & - & - & - & - \\
\hline Dibuat keripik & - & - & - & - \\
\hline \multicolumn{5}{|l|}{ Pengolahan Sayur } \\
\hline Berkuah bening & $13(76,5)$ & $14(82,4)$ & $12(70,6)$ & $14(82,4)$ \\
\hline Berkuah santan & $1(5,9)$ & - & - & - \\
\hline Tumis & $3(17,6)$ & $3(17,6)$ & $5(29,4)$ & $3(17,6)$ \\
\hline \multicolumn{5}{|l|}{ Ketersediaan buah } \\
\hline Selalu & $3(17,6)$ & $5(29,4)$ & $3(17,6)$ & $4(23,5)$ \\
\hline Kadang-kadang & $14(82,4)$ & $12(70,6)$ & $14(82,4)$ & $13(76,5)$ \\
\hline Tidak pernah & - & - & - & - \\
\hline \multicolumn{5}{|l|}{ Ketersediaan Sayuran } \\
\hline Selalu & $8(47,1)$ & $11(64,7)$ & $5(29,4)$ & $3(17,6)$ \\
\hline Kadang-kadang & $8(47,1)$ & $6(35,3)$ & $12(70,6)$ & $13(76,5)$ \\
\hline Tidak pernah & $1(5,9)$ & - & - & $1(5,9)$ \\
\hline \multicolumn{5}{|l|}{ Memasak di rumah } \\
\hline Selalu & $16(58,8)$ & $16(58,8)$ & $17(100)$ & $17(100)$ \\
\hline Kadang-kadang & $1(5,9)$ & $1(5,9)$ & - & - \\
\hline Tidak pernah & - & - & - & - \\
\hline
\end{tabular}

Sumber : Data Primer, 2018 
intervensi dan kontrol, dan selanjutnya digunakan uji post hoc (Bonferroni dan Mann-Whitney) untuk mengenalisis jenis intervensi yang paling berbeda/ berhubungan signifikan.

\section{HASIL}

Pendidikan ibu pada kelompok kontrol paling banyak pada tingkat SMP 7 orang $(41,2 \%)$, kelompok gabungan paling banyak pada tingkat SD dan SMA 6 orang $(35,3 \%)$, sedangkan pada kelompok permainan kartu paling banyak pada tingkat SD 6 orang $(35,3 \%)$, kemudian pada kelompok bernyanyi paling banyak pada kelompok SD dan SMA 5 orang $(29,4 \%)$ (Tabel 1).

Distribusi subjek penelitian berdasarkan pekerjaan ibu (orang tua) paling banyak dengan pekerjaan buruh pada masing-masing kelompok, pada kelompok kontrol 9 orang $(52,9 \%)$ dan intervensi kelompok gabungan dan permainan kartu 8 orang $(47,1 \%)$, serta pada kelompok teknik bernyanyi 7 orang $(41,2 \%)$. Kemudian distribusi subjek berdasarkan jumlah anggota keluarga paling banyak dengan jumlah 3 orang pada kelompok kontrol 10 anak $(58,8 \%)$, kelompok intervensi gabungan 8 anak $(47,1 \%)$ dan kelompok permainan kartu bergambar 8 anak $(47,1 \%)$, tetapi pada kelompok teknik bernyanyi paling banyak dengan jumlah anggora keluarga 4 orang sebanyak 11 anak $(64,7 \%)$ (Tabel 1).

Karakteristik subjek penelitian berdasarkan tingkat kesukaan mengonsumsi buah-buahan secara langsung baik pada kelompok kontrol dan kelompok intervensi 17 anak (100\%). Kemudian untuk pengolahan sayuran yang disukai anak-anak dengan cara dimasak dengan berkuah bening pada kelompok kontrol sejumlah 13 anak (76,5\%), dan pada kelompok intervensi gabungan dan teknik bernyanyi 14 anak $(82,4 \%)$ serta pada kelompok permainan kartu sejumlah 12 anak $(70,6 \%)$ (Tabel $1)$.

Ketersediaan buah pada masing-masing kelompok kontrol dan intervensi paling ba-

Tabel 2. Distribusi Frekuensi Subjek Penelitian Berdasarkan Sikap dan Perilaku Gizi

\begin{tabular}{lcccc}
\hline \multirow{2}{*}{ Variabel } & \multicolumn{2}{c}{ Sebelum } & \multicolumn{2}{c}{ Sesudah } \\
\cline { 2 - 5 } & $\mathbf{n = 6 8}$ & $\mathbf{\%}$ & $\mathbf{n = 6 8}$ & $\mathbf{\%}$ \\
\hline Sikap Gizi & & & & \\
$\quad$ Baik & 65 & 95,6 & 66 & 97,1 \\
$\quad$ Sedang & 3 & 4,4 & 1 & 1,5 \\
$\quad$ Kurang baik & 0 & 0 & 1 & 1,5 \\
Perilaku Gizi & & & & \\
$\quad$ Baik & 31 & 45,6 & 54 & 79,4 \\
$\quad$ Sedang & 37 & 54,4 & 14 & 20,6 \\
$\quad$ Kurang baik & 0 & 0 & 0 & 0 \\
\hline
\end{tabular}

Sumber: Data Primer, 2018

Tabel 3. Pengaruh Pendidikan Gizi terhadap Sikap dan Perilaku Gizi Sebelum dan Sesudah Intervensi

\begin{tabular}{llccc}
\hline \multirow{2}{*}{ Variabel } & \multicolumn{3}{c}{ Hasil Pengukuran } \\
\cline { 2 - 3 } & \multicolumn{1}{c}{ Kelompok } & \multicolumn{2}{c}{ Mean \pm SD } & p \\
\cline { 2 - 4 } Sikap & Kontrol & $6.49 \pm 1.11$ & $6.10 \pm 1.22$ & 0,326 \\
& Gabungan & $6.00 \pm 1.27$ & $7.38 \pm 0.98$ & $0,002^{*}$ \\
& Permainan kartu & $6.12 \pm 1.54$ & $6.46 \pm 1.71$ & 0,523 \\
& Teknik bernyanyi & $5.91 \pm 1.40$ & $6.50 \pm 1.27$ & 0,264 \\
& & & \\
\multirow{2}{*}{ Perilaku } & Kontrol & $9.25 \pm 1.53$ & $10.40 \pm 1.04$ & $0,023^{*}$ \\
& Gabungan & $10.09 \pm 1.01$ & $10.91 \pm 1.21$ & $0,022^{*}$ \\
& Permainan kartu & $9.53 \pm 1.39$ & $9.58 \pm 1.41$ & 0,880 \\
& Teknik bernyanyi & $9.56 \pm 1.850$ & $10.29 \pm 0.79$ & 0,144 \\
\hline
\end{tabular}

Sumber: Data Primer, 2018 
Tabel 4. Perbedaan Rerata Sikap dan Perilaku Gizi Sebelum dan Sesudah Pendidikan Gizi Pada Kelompok Intervensi dan Kontrol

\begin{tabular}{|c|c|c|c|c|c|}
\hline \multirow{2}{*}{ Variabel } & \multicolumn{4}{|c|}{ Kelompok Pengukuran } & \multirow{2}{*}{$\mathbf{p}$} \\
\hline & Kontrol & Gabungan & Permainan & Teknik Bernyanyi & \\
\hline \multicolumn{6}{|l|}{ Sikap Gizi } \\
\hline Rerata Pretest & $6.49 \pm 1.11$ & $6.00 \pm 1.27$ & $6.12 \pm 1.54$ & $5.91 \pm 1.40$ & 0,041 \\
\hline Rerata Postest & $6.10 \pm 1.22$ & $7.38 \pm 0.98$ & $6.46 \pm 1.71$ & $6.50 \pm 1.27$ & \\
\hline Selisih & -0.39 & 1.38 & 0.34 & 0.59 & \\
\hline \multicolumn{6}{|l|}{ Perilaku Gizi } \\
\hline Rerata Pretest & 29.85 & 40.03 & 33.24 & 34.88 & 0,001 \\
\hline Rerata Posttest & 35.68 & 49.06 & 22 & 31.26 & \\
\hline Selisih & 8.83 & 9.03 & $-11,24$ & -3.62 & \\
\hline
\end{tabular}

Sumber: Data Primer, 2018

nyak pada tingkat kadang-kadang dengan jumlah 14 anak $(82,4 \%)$ pada kelompok kontrol, pada kelompok intervensi gabungan berjumlah 12 anak $(70,6 \%)$, intervensi permainan kartu berjumlah 14 anak $(82,4 \%)$, dan intervensi teknik bernyanyi berjumlah 13 anak (76,5\%), dibandingkan dengan selalu tersedia buah-buahan di rumah. Kemudian ketersediaan sayur-sayuran dengan hasil kadangkadang untuk tersedia di rumah pada kelompok intervensi permainan kartu 12 anak (70,6\%) dan teknik bernyanyi sejumlah 13 anak (76,5\%), tetapi pada kelompok intervensi gabungan ketersediaan sayur-sayuran selalu tersedia di rumah sejumlah 11 anak $(64,7 \%)$ dibandingkan pada kelompok kontrol hasil distribusi frekuensi menunjukkan tingkat tersedia sayur di rumah dengan hasil selalu sama dengan tingkat ketersediaan kadang-kadang 8 anak (47,1\%), tetapi terdapat 1 anak (5,9\%) tidak pernah tersedia sayur di rumah (Tabel 1).

Distribusi frekuensi sikap dan perilaku gizi baik sebelum dan sesudah intervensi pada kelompok intervensi dan kontrol didapatkan terdapat perubahan sikap gizi baik yang meningkat sesudah intervensi $(97,1 \%)$ dari sebelum intervensi $(95,6 \%)$. Hal ini menunjukkan bahwa intervensi pendidikan gizi yang diberikan dapat merubah sikap gizi yang lebih baik. Selanjutnya, terdapat perubahan perilaku gizi baik yang meningkat sesudah intervensi $(45,6 \%)$ dari sebelum intervensi $(79,4 \%)$. Hal ini menunjukkan bahwa intervensi pendidikan gizi yang diberikan dapat merubah perilaku gizi yang lebih baik (Tabel 2).

Variabel sikap gizi terdapat peningkatan rerata skor antara sebelum dan sesudah intervensi pada kelompok kontrol, intervensi gabungan dan permainan kartu serta teknik bernyanyi. Hasil uji statistik paired $t$ test pada kelompok intervensi gabungan terdapat perbedaan yang bermakna $(\mathrm{p}=$ 0,002) (Tabel 3).

Variabel perilaku gizi menunjukkan adanya peningkatan rerata skor antara sebelum dan sesudah intervensi pada kelompok kontrol, intervensi gabungan dan permainan kartu serta teknik bernyanyi. Hasil uji statistik paired t test pada kelompok kontrol terdapat perbedaan yang bermakna $(\mathrm{p}=0,023)$ dan pada intervensi gabungan terdapat perbedaan yang bermakna ( $\mathrm{p}=0,022)$ (Tabel 3$)$.

Sikap gizi berdasarkan nilai pre test dan post test terdapat hasil rerata pre test dan post test sikap gizi pada kelompok gabungan dan teknik bernyanyi lebih tinggi dibandingkan dengan kelompok kontrol dan permainan kartu. Rerata selisih pre test dan post test paling tinggi terdapat pada kelompok gabungan (1.38), sedangkan selisih paling rendah pada kelompok kontrol (-0.39). Hasil uji statistik didapat nilai $\mathrm{p}=0,041$ dapat disimpulkan ada perbedaan sikap gizi diantara empat kelompok intervensi pendidikan gizi. Analisis lebih lanjut menggunakan uji Bonferroni menunjukkan kelompok yang berbeda signifikan adalah kelompok kontrol dengan gabungan $(\mathrm{p}=0,037)$ (Tabel 4).

Perilaku gizi berdasarkan nilai pre test dan post test terdapat hasil rerata pre test dan post test perilaku gizi pada kelompok gabungan dan kontrol lebih tinggi dibandingkan dengan permainan kartu dan teknik bernyanyi. Rerata selisih pre test dan post test paling tinggi terdapat pada kelompok gabungan (8.83), sedangkan selisih paling rendah pada kelompok permainan kartu (-11.24). Hasil uji 
statistik Kruskal-Wallis didapat nilai $\mathrm{p}=0,001$ dapat disimpulkan ada perbedaan perilaku gizi diantara empat kelompok intervensi pendidikan gizi. Analisis lebih lanjut menggunakan uji Mann-Whitney menunjukkan bahwa kelompok yang berbeda signifikan adalah kelompok kontrol dengan gabungan $(p=0,038)$, kontrol dengan permainan kartu $(p=0,045)$, intervensi gabungan dengan permainan kartu ( $p \leq 0,001)$, serta intervensi gabungan dengan teknik bernyanyi $(p=0,005)$ (Tabel 4$)$.

\section{PEMBAHASAN}

Pendidikan ibu yang rendah berpengaruh pada pengetahuan dan pemenuhan gizi pada anakanak. ${ }^{11}$ Orang dengan pendidikan tinggi cenderung memiliki pengetahuan lebih banyak tentang manfaat buah dan sayuran, dengan frekuensi sering untuk mengonsumsi buah dan sayuran. ${ }^{12}$ Hasil penelitian diperoleh informasi bahwa pendidikan ibu paling banyak dengan tingkat lulusan SD menunjukkan perhatian tentang gizi pada anak-anak yang tidak baik, sejalan dengan hasil kesediaan buah dan sayuran di rumah dengan frekuensi kadangkadang menunjukkan rendahnya pengetahuan ibu tentang pemenuhan gizi bagi anak-anak dan keluarga.

Pendukung dari sikap anak dalam memilih makanan berkaitan dengan jumlah anggota keluarga yang sedikit di rumah berhubungan dengan kasih sayang dan perhatian orang tua yang diberikan pada anak. ${ }^{13}$ Sejalan dengan penelitian pada ibu yang lebih muda (produktif) memiliki rasa "demokratis" dan "terlalu protektif" menampilkan sikap yang lebih positif dalam mengembangkan kebiasaan makan anak. ${ }^{14}$

Penelitian menunjukkan bahwa pemodelan peran orang tua dari perilaku makan yang sehat berkorelasi positif dengan sikap, perilaku dan asupan buah dan sayuran pada anak-anak. Oleh karena itu, orang tua harus didorong untuk memanfaatkan kesempatan dalam memberikan contoh pola makan sehat serta mengonsumsi buah dan sayuran. ${ }^{15}$ Hasil dari penelitian ini mendukung penerapan model Attitude-Social Influence-Self-Efficacy (ASE) pada orang tua yang menunjukkan bahwa beberapa praktik pemberian makanan oleh orang tua memiliki pengaruh pada niat dan perilaku anak mengenai konsumsi buah dan sayuran. ${ }^{16}$

Pendidikan gizi yang berorientasi akademis dimasukkan ke dalam kurikulum kegiatan mengajar termasuk bahasa, sains, seni, matematika, musik dan pendidikan jasmani, sebagai alat pembelajaran yang digunakan untuk perkembangan motorik anak-anak. ${ }^{17}$ Penelitian ini menunjukkan bahwa melalui intervensi gabungan (bernyanyi dan permainan kartu) dapat meningkatkan perubahan sikap gizi yang lebih baik. Sejalan dengan permainan kartu dan bernyanyi dapat meningkatkan interaksi sosial dan psikologis di antara orang-orang yang ikut bermain sehingga siswa sangat tertarik dengan permainan dan mau belajar melalui permainan untuk membangun pengetahuan melalui permainan. ${ }^{18,19}$

Peningkatan sikap gizi yang baik pada penelitian ini sejalan dalam penelitian yang menggunakan intervensi gabungan menunjukkan hasil bahwa pendidikan gizi multikomponen menghasilkan perubahan yang positif terkait pengetahuan, sikap dan keyakinan terhadap buah dan sayuran. ${ }^{20}$ Selanjutnya, sejalan dengan permainan dari video clip pendek, analisis ini memberikan bukti bahwa permainan berfungsi sebagai infrastruktur yang efektif untuk belajar, karena permainan menguraikan skrip sosial bagi siswa untuk berkumpul dan memproses materi tentang topik yang relevan dengan memberikan pengetahuan baru yang didasarkan pada artefak epistemik khusus yang disesuaikan, pengamatan pada praktik pedagogis dan secara reflektif menghubungkannya dengan sikap profesional juga menunjukkan kepekaan terhadap perbedaan antar siswa sebagai bagian dari kegiatan reflektif. ${ }^{21}$ Permainan yang berkolaborasi dari aspek seni yang dibantu teknologi yang mendukung anak taman kanak-kanak untuk pengembangan dalam tiga dimensi meliputi : fisik, sosio-afektif dan kognitif. Oleh karena itu, teknologi permainan cocok untuk mendukung peningkatan dan pengembangan sikap dan perilaku anak-anak..$^{22}$

Pendidikan pada anak taman kanak-kanak melalui bernyanyi yang sesuai dengan karakter anak-anak akan membentuk perkembangan psikologis yang memfasilitasi kreativitas mereka. Belajar sambil bernyanyi merupakan cara yang efektif membuat siswa/peserta didik untuk belajar mengekspresikan diri melalui instrumen, serta melalui gerakan kreatif dan tarian untuk membentuk keceriaan pada masa yang datang. ${ }^{23,24} \mathrm{Hal}$ ini sejalan dengan lagu yang digunakan pada pene- 
litian ini menggunakan lirik lagu yang sederhana dan nada yang sesuai dengan anak-anak sehingga terdapat peningkatan sikap gizi yang baik.

Bernyanyi dan bermain kartu pada penelitian ini merupakan pendidikan yang memiliki perencanaan pembelajaran dengan konsep belajar sambil bermain. Kegiatan pendidikan gizi berbasis sensori dapat mempromosikan keinginan untuk makan sayur dan buah. ${ }^{25}$ Sejalan pada pendidikan dengan berkebun dengan acuan kurikulum merupakan instruksi gizi yang memiliki efek positif dapat meningkatkan sikap anak-anak terhadap makan buah dan sayuran. ${ }^{26}$ Namun, berbeda pada pendidikan menggunakan kurikulum, tidak terdapat perbedaan yang bermakna antara pengetahuan dan sikap siswa SMA yang menerapkan pendidikan mulok ilmu gizi berbasis makanan khas daerah. ${ }^{27}$

Penerapan penekanan pendidikan berkelanjutan mengeksplorasi cara-cara di mana sifat bermain dan konsep keberlanjutan sangat penting dan dapat dikembangkan dan ditindaklanjuti anak taman kanak-kanak diikuti fokus pada nilai-nilai pedagogik yang menghubungkan aspek bermain secara keberlanjutan. ${ }^{28}$ Intervensi gabungan memberikan dampak yang signifikan terhadap peningkatan perilaku gizi terkait buah dan sayuran. Hal ini berkaitan pada penelitian yang menujukkan bahwa jaringan syaraf sensorik dan auditori dari suara nyanyian, mulai dari saluran vokal dan mengarah ke daerah otak yang terlibat dalam bernyanyi merupakan hubungan antara respon dari otak dan perilaku yang menjadi output dari bernyanyi, melalui bernyanyi informasi yang disampaikan akan tercapai apabila didengarkan dengan fokus. ${ }^{29,30}$ Selanjutnya, karakteristik perseptual dan kognitif dari kartu secara khusus, berhubungan dengan visibilitas, memori, daya tarik, dan aksesibilitas verbal serta visual menunjukkan bahwa rangsangan yang diterima dapat diingat dan dipersepsikan. ${ }^{31}$

Sejalan dengan penelitian yang dilakukan pada kelompok media edukasi gizi yang diberikan melalui gabungan antara website dan android menunjukkan bahwa terdapat peningkatan perubahan yang positif pada perilaku tentang gizi seimbang pada anak Sekolah Dasar. ${ }^{32}$ Serta pada penelitian yang menerapkan pendidikan gizi melalui kurikulum karyawisata dengan turun langsung ke perkebunan menunjukkan hasil secara positif mempengaruhi pengetahuan gizi anak-anak usia sekolah dan perilaku konsumsi buah dan sayuran. ${ }^{33}$ Namun, hasil yang berbeda pada penelitian pendidikan gizi menggunakan media animasi menunjukkan tidak ada perbedaan yang bermakna terhadap perilaku konsumsi buah dan sayuran pada anak-anak, ${ }^{34}$ dan didapatkan hasil penelitian yang menunjukan bahwa pendidikan gizi menggunakan permainan sensori/mencicipi langsung buah dan sayuran lebih mendorong peningkatan perilaku konsumsi buah dan sayuran pada anak taman kanak-kanak dibandingkan dengan pendidikan gizi menggunakan permainan non makanan dan paparan visual. ${ }^{35}$ Selanjutnya, penelitian pada balita untuk melihat dan membaca buku tentang buah dan sayuran dengan pendampingan orang tua dapat meningkatkan perilaku konsumsi buah dan sayuran dibandingkan dengan kelompok kontrol. ${ }^{36}$ Hal ini berkaitan dalam menargetkan perubahan perilaku anak-anak harus dilandasi dalam berbagai aspek seperti lingkungan, dukungan orang tua dan pendidikan gizi yang diberikan. ${ }^{37}$ Serta masalah keterlambatan perubahan perilaku anak berkaitan dengan substansial bahasa, respon motorik dan keterampilan sosioemosional. Oleh karena itu, diperlukan penyaringan dan intervensi dini sebelum melakukan proses pendidikan..$^{38}$

Intervensi yang diberikan pada kelompok gabungan (bernyanyi dan permainan kartu bergambar) juga dilakukan pendekatan ke anak-anak dalam penyampainan pesan dari pendidikan tersebut. Sejalan dengan penelitian dengan menerapkan pendekatan ke anak-anak dalam pendidikan gizi dapat menghasilkan efek yang menguntungkan dan keuntungan dalam mempromosikan perilaku gizi di kalangan anak-anak prasekolah. ${ }^{39}$ Namun, perlu diperhatikan hasil penelitian menunjukkan bahwa keberhasilan pemahaman pesan dari belajar sambil bermain pada anak taman kanak-kanak berkaitan dengan keaktifan guru dalam mengkondisikan permainan dan lingkungan kelas. ${ }^{40}$ Serta penelitian terkait pendidikan gizi di sekolah didapatkan hasil pengetahuan dan perilaku konsumsi buah dan sayuran yang meningkat dengan intervensi gabungan (kampanye pendidikan gizi dan melibatkan orang tua) untuk menerapkan makanan sehat pada anak-anak. ${ }^{4}$ 


\section{KESIMPULAN DAN SARAN}

Nilai sikap dan perilaku gizi meningkat setelah pemberian intervensi gizi menggunakan media teknik bernyanyi, dan permainan kartu serta gabungan. Pendidikan gizi melalui intervensi gabungan dapat meningkatkan sikap dan perilaku gizi terkait buah dan sayuran pada anak-anak dibandingkan dengan intervensi permainan kartu, teknik bernyanyi dan kelompok kontrol.

Saran yang dapat diberikan meliputi : intervensi untuk meningkatkan sikap dan perilaku gizi pada anak-anak sebagai pendidikan gizi sejak dini disampaikan melalui teknik bernyanyi dan permainan kartu bergambar, diperlukan kerjasama lebih lanjut dari setiap stakeholder untuk menyosialisasikan media pendidikan gizi dalam peningkatan sikap dan perilaku gizi pada anak-anak dengan mengikut sertakan orang tua, dan diperlukan penelitian lebih lanjut terkait pendidikan gizi dengan mengikut sertakan orang tua (ibu) sebagai penentu dari menu buah dan sayuran yang disajikan di rumah.

\section{DAFTAR PUSTAKA}

1. Kementerian Kesehatan RI. Buku Panduan Gerakan Masyarakat Hidup Sehat (GERMAS). Jakarta : Kementerian Kesehatan RI; 2016.

2. Kementerian Kesehatan RI. Profil Penyakit Tidak Menular Tahun 2016. Jakarta. Kementerian Kesehatan RI; 2017.

3. Loprinzi PD, Schary DP, Cardinal BJ. Adherence to Active Play and Electronic Media Guidelines in Preschool Children: Gender and Parental Education Considerations. Matern Child Health J. 2013;17(1):56-61.

4. Kennedy-Behr A, Rodger S, Mickan S. A Comparison of the Play Skills of Preschool Children with and without Developmental Coordination Disorder. OTJR OccupParticip Heal. 2013;33(4):198-208.

5. Supariasa IDN. Pendidikan dan KonsultasiGizi. Jakarta : Penerbit Buku Kedoktean EGC; 2012.

6. Mardhiati. Penggunaan Media Audio (Lagu Anak-Anak) dalam Edukasi Gizi Seimbang Pada Anak Usia Prasekolah [Skripsi]. Makassar : Universitas Hasanuddin; 2015.

7. Nugraha G. Pengembangan Kreativitas Anak
Usia Dini melalui Pendekatan Musik [Skripsi]. Bandung: Pendidikan Luar Sekolah Fakultas Ilmu Pendidikan Universitas Pendidikan Indonesia; 2007.

8. Torkar G, Pintarič M, Koch V. Fruit and Vegetable Playing Cards. Nutr Food Sci. 2010;40(1):74-80.

9. Briawan D, Ikeu E dan Ratu DK. Pengaruh Media Kampanye Sarapan Sehat terhadap Perubahan Pengetahuan, Sikap, dan Kebiasaan Sarapan Anak Sekolah Dasar di Kabupaten Bogor. Jurnal Gizi dan Pangan. 2013;8(2): 115-122. ISSN 1978 - 1059.

10. Murti B. Desain dan Ukuran Sampel untuk Penelitian Kuantitatif dan Kualitatif di Bidang Kesehatan. Yogyakarta : UGM Press. 2013. ISBN : 979-420-806-X.

11. Anwar S, Nasreen S, Batool Z, Husain Z. Maternal Education and Child Nutritional Status in Bangladesh: Evidence from Demographic and Health Survey Data. Pakistan J Life Soc Sci. 2013;11:77-84.

12. Nti CA, Hagan J, Bagina F, Seglah M. Knowledge of Nutrition and Health Benefits and Frequency of Consumption of Fruits and Vegetables among Ghanaian Homemakers. African J Food Sci. 2011;5(6):333-9.

13. Marmi. Gizi dalam Kesehatan Reproduksi. Yogyakarta : Pustaka Pelajar; 2013.

14. Ozgen L, Demiriz S. Determining Mothers' Attitude in Developing Preschool Children' Eating Behaviours. Procedia - SocBehav Sci. 2015;191:662-7.

15. Draxten M, Fulkerson JA, Friend S, Flattum CF, Schow R. Parental Role Modeling of Fruits and Vegetables at Meals and Snacks is Associated with Children's Adequate Consumption. Appetite. 2014;78:1-7.

16. Melbye EL, Overby NC, Ogaard T. Child Consumption of Fruit and Vegetables: The Roles of Child Cognitions and Parental Feeding Practices. Public Health Nutr. 2012;15(6):104755.

17. Gao Y, Huang Y, Zhang Y, Liu F, Feng CX, Liu T, et al. Evaluation of Fast Food Behavior in Pre-school Children and Parents Following a One-Year Intervention with Nutrition Education. Int J Environ Res Public Health. 2014;11(7):6780-90. 
18. Chen PG, Liu EZF, Lin CH, Chang WL, Hsin TH, Shih RC. Developing an Education Card Game for Science Learning in Primary Education. In: 2012 IEEE Fourth International Conference On Digital Game And Intelligent Toy Enhanced Learning. IEEE; 2012. p. 236-40.

19. Keeler JR, Roth EA, Neuser BL, Spitsbergen JM, Waters DJM, Vianney J-M. The NeuroChemistry and Social Flow of Singing: Bonding and Oxytocin. Front Hum Neurosci. 2015;9.

20. Prelip M, Kinsler J, Thai C Le, Erausquin JT, Slusser W. Evaluation of a School-Based Multicomponent Nutrition Education Program to Improve Young Children's Fruit and Vegetable Consumption. J Nutr Educ Behav. 2012;44(4):310-8.

21. Routarinne S, Ylirisku S. Video Card Game as a Learning Design for Teacher Education. Procedia - Soc Behav Sci. 2012;45:370-80.

22. Nacher V, Garcia-Sanjuan F, Jaen J. Interactive Technologies for Preschool Game-Based Instruction: Experiences and Future Challenges. Entertain Comput. 2016;17:19-29.

23. Liao MY, Campbell PS. An Analysis of Song-Leading by Kindergarten Teachers in Taiwan and the USA. Music Educ Res. 2014;16(2):144-61.

24. Nacher V, Garcia-Sanjuan F, Jaen J. Game Technologies for Kindergarten Instruction: Experiences and Future Challenges. In: CEUR Workshop Proceedings. 2015. p. 58-67.

25. Hoppu U, Prinz M, Ojansivu P, Laaksonen O, Sandell MA. Impact of sensory-based food education in kindergarten on willingness to eat vegetables and berries. Food Nutr Res. 2015;59.

26. Nolan GA, Mcfarland AL, Zajicek JM, Waliczek TM. The Effects of Nutrition Education and Gardening on Attitudes, Preferences, and Knowledge of Minority Second to Fifth Graders in the Rio Grande Valley toward Fruit and Vegetables. Horttechnology. 2012;22(3):299-304.

27. Dali NA. Pengaruh Penerapan Muatan Lokal Ilmu Gizi Berbasis Makanan Khas Daerah Gorontalo Terhadap Perilaku Gizi Siswa SMU di Kota Gorontalo. Jurnal MKMI. 2013;9(3):139-146.
28. Haas C, Ashman G. Kindergarten Children's Introduction to Sustainability Through Transformative, Experiential Nature Play. Aust J Early Child. 2014;39(2):21-9.

29. Zarate JM. The Neural Control of Singing. Front Hum Neurosci [Internet]. 2013;7. [Diakses 25 Maret 2018] Availabel at: http:// journal.frontiersin.org/article/10.3389/fnhum.2013.00237/abstract.

30. Goto M. Singing Information Processing. In: International Conference on Signal Processing Proceedings, ICSP. 2014. p. 2431-8.

31. Olson JA, Amlani AA, Rensink RA. Perceptual and Cognitive Characteristics of Common Playing Cards. Perception. 2012;41(3):26886.

32. Perdana F, Madanijah S, Ekayanti I. Pengembangan Media Edukasi Gizi Berbasis Android dan Website serta Pengaruhnya terhadap Perilaku Tentang Gizi. 2017;12:169-78.

33. Moss A, Smith S, Null D, Long Roth S, Tragoudas U. Farm to School and Nutrition Education: Positively Affecting Elementary School-Aged Children's Nutrition Knowledge and Consumption Behavior. Child Obes. 2013;9(1):51-6.

34. Anggraeni E. Perbedaan Pengaruh Pelajaran Gizi Menggunakan Media Animasi dan Ceramah Terhadap Pengetahuan Gizi, Sikap dan Perilaku Konsumsi Buah dan Sayur Pada Anak Sekolah Dasar [Tesis]. Surakarta : Universitas Sebelas Maret; 2015.

35. Coulthard H, Sealy A. Play with Your Food! Sensory Play is Associated with Tasting of Fruits and Vegetables in Preschool Children. Appetite. 2017;113:84-90.

36. Heath P, Houston-Price C, Kennedy OB. Let's Look at Leeks! Picture Books Increase Toddlers' Willingness to Look at, Taste and Consume Unfamiliar Vegetables. Front Psychol. 2014;

37. Bourke M, Whittaker PJ, Verma A. Are Dietary Interventions Effective at Increasing Fruit and Vegetable Consumption among Overweight Children? A Systematic Review. J Epidemiol Community Health. 2014;68(5):485-90.

38. Montes G, Lotyczewski BS, Halterman JS, Hightower AD. School Readiness among Children with Behavior Problems at Entrance 
into Kindergarten: Results from a US national study. Eur J Pediatr. 2012;171(3):541-8.

39. Y. D, J.-L. W, L.-L. W, M.-Q. C. Impact of Nutrition Education through Child-to-Child Approach on Diet Behaviors among Preschool Children [Internet]. Journal of Shanghai Jiaotong University (Medical Science). 2013; 33: 1135-40.

40. Pyle A, Alaca B. Kindergarten Children's Per- spectives on Play and Learning. Early Child Development and Care. 2016;1-13.

41. Blitstein JL, Cates SC, Hersey J, Montgomery D, Shelley M, Hradek C, et al. Adding a Social Marketing Campaign to a School-Based Nutrition Education Program Improves Children's Dietary Intake: A Quasi-Experimental Study. J Acad Nutr Diet. 2016;116(8):1285-94. 